\title{
O ESTUDO DOS ESPAÇOS PÚBLICOS METROPOLITANOS: A PRAÇA DA ALFÂNDEGA EM PORTO ALEGRE O COTIDIANO DOS AGREGADOS SOCIAIS
}

\author{
Luciano Fernandes Pedroso*
}

* Doutorando em Geografia no Programa de Pós-Graduação em Geografia da Universidade Federal do Rio Grande do Sul (PPG-UFRGS). Bolsista CAPES. E-mail: luccgeo@gmail.com

Recebido em 12/2014. Aceito para publicação em 05/2015. Versão online publicada em 13/01/2016 (http://seer.ufrgs.br/paraonde)

\begin{abstract}
Resumo: 0 objetivo do presente trabalho foi estudar o cotidiano dos agregados sociais da Praça da Alfândega, localizada no centro da cidade de Porto Alegre (Rio Grande Sul, Brasil). Foram investigados, no âmbito desse espaço, os aspectos relacionais, identitários, as expressões subjetivas e estéticas, as fronteiras de convivências, assim como as territorializações empreendidas pelos indivíduos que compõem esses agregados sociais no espaço da Praça da Alfândega. Além disso, neste artigo são discutidas questões pertinentes sobre a função do espaço público, a cidadania e os aspectos relativos às formas de sociabilidade e de insociabilidade nas metrópoles contemporâneas. Pode-se dizer que a Praça da Alfândega, como mosaico de representações sociais, territórios justapostos e signos ,constitui um importante lócus de análise do espaço urbano. Com efeito, ela se apresenta para as formas sociais denominadas agregados sociais como um espaço dicotômico da sobrevivência material e da convivência social. Por esse motivo, o estudo do cotidiano dos agregados sociais presentes no espaço da Praça da Alfândega constitui também uma investigação sobre os fenômenos urbanos contemporâneos; e as múltiplas e emergentes práticas sociais desses agregados se manifestam nos estilos de vida, nas formas simbólicas e nos usos dos espaços nas grandes metrópoles.
\end{abstract}

Palavras-chave: Cotidiano - Agregado social - Espaço urbano - Identidade.

\section{Os agregados sociais da Praça da Alfândega}

"Somos do tecido com o qual se fazem os sonhos"

(Shakespeare)

Este artigo é originário das minhas pesquisas desenvolvidas no mestrado trazendo como contribuição o estudo das práticas socioespaciais estabelecidas na Praça da Alfândega, este importante espaço público do centro de Porto Alegre, onde circulam milhares de pessoas diariamente, e que podemos perceber as articulações de vários agregados sociais que convivem cotidianamente e se apropriam ou utilizam de parcelas deste espaço público. Isto ocorre por diferentes motivos, que vão desde a necessidade de sobrevivência (prostituta, engraxates e vendedores ambulantes) até como ponto de encontro, ócio e lazer (idosos, jogadores de damas e dominós, etc), assim como os transeuntes que utilizam o espaço para simples deslocamento para outros pontos da cidade (o que não se considera como sendo agregados sociais).

A partir desta discussão o conceito que mais representava a realidade verificada neste espaço foi o de agregado social onde Pérsio Santos de Oliveira (2005, p.67) o define como a "reunião de pessoas com fraco sentimento grupal e frouxamente aglomeradas. Mesmo assim, conseguem manter entre si um míni- mo de comunicação e de relações sociais, sendo as pessoas que dele participam relativamente anônimas

Os agregados sociais descritos constituem territorialidades efêmeras e elásticas no que se refere às fronteiras de convivências estabelecidas no espaço da Praça da Alfândega. Para analisar as fronteiras de convivência, marcadas pela identidade e identificação ou por relações de poder além do aspecto relacional empreendida pelos indivíduos nesse espaço deve-se ter umapreocupação especifica quanto às referências de poderes simbólicos expressos nas relações socioespaciais.

Esse aspecto surge com grande importância nesta análise, pois inúmeras dessas fronteiras de convivências estabelecidas convergem expressivamente de maneira simbólica, conjugadas com uma lógica de identificação social que muitas vezes torna-se um elemento conflitante facilmente perceptível na escala deste lugar. Sobre questão simbólica Bourdieu (2001, p.10) afirma que, "Os símbolos são os instrumentos por excelência da 'integração social': enquanto instrumentos de conhecimento e de comunicação (...) eles tornam possível o consensus acerca do sentido do mundo social que contribui fundamentalmente para a reprodução da ordem social". Símbolos, os quais, que não podem deixar de ser analisados no estudo dos agregados sociais da Praça da Alfândega. De acordo com Campos (2002, p. 37), "As formas de expressão de poder dizem respeito ao controle 
sobre o acesso a áreas específicas, sobre as relações, sobre comportamentos; essas relações de poder podem se dar nos mais diversos níveis, apresentando ou não sinais concretamente estabelecidos no espaço".

Isso leva também a recolocar a questão das identidades individuais e coletivas, porque se a identidade dos grupos, por diversas que sejam suas origens, depende do dispositivo espacial que os funda e os reúnem, as novas configurações urbanas e os dispositivos de comunicação planetária, ao questionar a estabilidade do território, colocam, por sua vez, novos problemas relativos a uma ideia e a um sentimento de comunidade e pertencimento.

A partir disso pode-se levar em conta diversos aspectos como a questão do gênero, da subjetividade, da identidade, da ética, da estética entre outros aspectos relevantes. Assim sendo, essas considerações denotam a complexidade do espaço urbano contemporâneo que conferem profundas e rápidas transformações na sociedade. Nessa ótica Laitano (1991, p.256) citando Maffesoli chama a atenção sobre as áreas metropolitanas atuais, as quais se colocam frente às "novas formas elaboradas hoje em dia", que sendo visíveis ou subterrâneas, apontam para uma multiplicidade do eu e a uma emergência do sentimento coletivo, construindo-se uma sociabilidade empática a qual vai se apresentar por meio de um mosaico de sentimentos, emoções e formas simbólicas. Com a criação de uma atmosfera e de um feeling próprios aos grupos, configuram-se as chamadas comunidades emocionais, cujas grandes características são "o aspecto efêmero, a 'composição cambiante', a inscrição local, 'a ausência de uma organização' e a estrutura cotidiana”.

Essa "emoção partilhada", conforme Laitano (1991, p.256), resulta na "constituição de um laço social num estar-junto comunitário", com partilha de um território configuram-se em conjuntos sociais que perpassam pela solidariedade presente na vida cotidiana das cidades contemporâneas. Portanto os agregados sociais presentes neste espaço público convergem numa fonte inesgotável de análises que serão abordadas no contexto da pesquisa.

\section{0 cotidiano da Praça da Alfândega: 0 espaço da convivência e da diferença}

Para trabalhar com questões do cotidiano e convivência no espaço público da Praça da Alfândega devem-se levar em consideração algumas questões em relação ao aspecto da socialidade e consequentemente sobre as formas de territorializações estabelecidas neste lugar específico. A convivência neste espaço conforme verificado nesta pesquisa através das entrevistas realizadas com os agregados sociais da Pra- ça da Alfândega constatou-se uma lógica de apropriação espacial diferenciada de acordo com os interesses desses agregados.

Neste caráter da convivência pode-se notar que há uma manifestação clara por parte dos idosos que utilizam este espaço como um possível lugar da fuga da solidão. E isto é muito presente na fala dos mesmos como relata um dos idosos entrevistados em um dos bancos da praça. Assim fala ele:

Aqui eu me sinto bem, não fico sozinho em casa. Falo com meus amigos de banco sobre muitas coisas. Política, a violência e não pode faltar o futebol, embora meu time não anda muito bem nas tabelas. Além disso, olhar as moçoilas que passam por aí. Tem cada uma de tirar o chapéu.

Neste relato pode-se destacar que a Praça da Alfândega tornou-se o ponto de encontro convergindo em uma forma de socialidade, revelada como uma alternativa à solidão. A menção da palavra banco como um elemento identificatório e simbólico que é revelada na fala deste idoso. Entende-se como a união entre as subjetividades constituída na relação entre sujeitos sendo ela marcada pelo aspecto comunicacional e onde o objeto concreto que marca este encontro, ou seja, o banco extrapola o significado de apenas um objeto inanimado tornando-se referência para uma prática social.

A ideia de socialidade e da interação do indivíduo com o outro também é palco de estudo de Edgar Morin (2003, p.78) no qual relata que "os sujeitos se auto-organizam em interação com os outros sujeitos. Assim o sujeito estrutura-se pela mediação dos outros sujeitos antes mesmos de conhecê-lo de fato". Esta convivência humana é marcada pela interação social conformada a partir da interdependência social, marcada pela experiência coletiva. Essa experiência denota-se por meio de significados que são revelados no estudo do cotidiano dos agregados sociais neste espaço urbano. De acordo com Rocha e Eckert (2005, p.92), "a cidade é, sem dúvida, um repositório de excedente de sentidos, e, em seus territórios, os sujeitos vivem cotidianamente estratégias de realidade, de opções de consumo, de escolhas de interação (...)".

No caso especifico da Praça da Alfândega, nesse aspecto analisado, a necessidade da convivência humana pode ser claramente percebida nos idosos pesquisados. Onde todos afirmaram que utilizam esse espaço para o contato com o próximo. A interação social pode aqui, ser entendida como a forma com que os indivíduos se relacionam mediadas pela comunicação, nesse caso a fala, é marcadamente a motivação pelos quais esses agregados sociais territorializam-se na Praça da Alfândega.

A superposição das experiências afetivas marcadas por esses agregados sociais estabelecidos na Praça da Alfândega, muitos deles são ritualizados e enraizados no sentido de fazerem deste espaço palco 
das principais práticas da vida social destes indivíduos. Esta ideia funda a Praça da Alfândega, também, como um lugar da diferença, ou seja, da apresentação de diversas formas, códigos, comportamentos, trajetos, papéis sociais que estão compreendidos e facilmente perceptíveis nesse espaço.

Nesse sentido, essa polissemia muitas vezes não é bem aceita por alguns agregados sociais que lá se territorializam, como pode se perceber na fala de um idoso que frequenta há vinte anos a Praça da Alfândega:

Aqui já foi lugar 'direito' hoje tem de tudo... drogas, mulheres da vida, vagabundos (...) uma 'cambada' de desocupados, chega uma hora da tarde que temos que ir embora, pois aqui só tem bandidagem, principalmente na sexta-feira (...) eu respeito eles. Eles que não me respeitam. Principalmente aquelas lá (se referindo as prostitutas).

Ainda nessa abordagem outro idoso entrevistado contaria o relato anterior afirmando sobre a praça o seguinte:

Aqui todos se entendem, cada um na sua. A praça é de todos. Não adianta reclamar. Quem não tá de acordo é que vá embora. Todos precisamos desse lugar para viver.

Nestes dois diálogos percebem-se as divergências de ideias entre os dois entrevistados. No primeiro o estranhamento perante a diferença e o modo de vida apresentado. No segundo a acomodação social, ou seja, a aceitação da diferença e dos papéis sociais emergentes nesse espaço.

Mas como se dá essa relação ambivalente da aceitação ou renegação do sujeito?

Haesbaert (1999, p.173) afirma que as relações implicadas no espaço, a convivência espacial que decorre da territorialidade se estabelece por meio da "identidade" numa "relação de semelhança ou de igualdade". Essa conformação pode ser entendida em um contexto espacial como uma lógica do pertencimento compartilhado, onde o indivíduo se sente identificado com o lugar e aceita o partilhamento desse espaço representado pela diferença.

No mesmo contexto Costa (2002, p. 69) ressalta,

Mesmo sendo uma busca individual, a identidade se dá por um processo relacional. Muitas vezes a pessoa procura experiências relacionais que não são precisas e, pelas relações afetivas que mantém, começa a entrar em contato com uma diversidade de meios sociais e elege as que lhe dão mais prazer e realizam alguns de seus interesses.

Essas relações se constituem por meio das relações afetivas que são conformadas no espaço a partir do estabelecimento de comportamentos diferenciados, revelados a partir de uma série de regras criadas pelos agregados que denotam fronteiras de convivências verificadas em partes do espaço.

Pode-se afirmar que essas fronteiras de convivências refletem em um processo de segregação espacial por parte de alguns agregados. Portanto a diferença, que como foi mencionado, é marcada pelos aspectos comportamentais e estéticos refletem em "uma imaginação da vida pública na qual as pessoas se comportam e controlam seu comportamento somente por meio de retraimento, conciliação e apaziguamento" (Sennett, 1998, p.55). Tem-se assim a perspectiva que os aspectos marcados pela convivência relacional dinamizam ou são motrizes das territorializações estabelecidas em um determinado espaço. Esse jogo nas relações interpessoais no cotidiano que nos pode remeter ao que Michel De Certeau (1994) chama das "astúcias de caçadores" ou "astúcias milenares" desempenhadas no convívio em sociedade. Para Maffesoli (2004, p.95-96) "o indivíduo é a causa e efeito da lógica da identidade" e essa identificação se dá a partir do desempenho dos papéis em conjunto com outros indivíduos.

Essa função dos papéis sociais é importante na análise de espaços públicos, principalmente quando estes estão nas grandes cidades metropolitanas, como é o caso da Praça da Alfândega. Como se refere Bauman (2004, p.135).

Viver na cidade é sabidamente uma experiência ambígua. A cidade atrai e repele, mas, para tornar a situação de seus habitantes ainda mais complexa, são os mesmos aspectos da vida que de modo intermitente ou simultâneo, atraem e repelem (...).

Além dos idosos que utilizam a Praça da Alfândega com o intuito do estar-junto outros agregados também dispõem deste espaço para este fim. Estes agregados são os jogadores de dama e dominós que já são elementos visíveis quase que obrigatórios para quem passa pela Praça da Alfândega. Geralmente formados por aposentados, moradores de rua e desempregados, os jogadores de damas e dominós utilizam cotidianamente este espaço para a ludicidade e também para a prática do convívio com outros indivíduos que lá se estabelecem com a mesma finalidade.

Ao entrevistá-los ao longo desta pesquisa nota-se claramente uma relação de vínculo espacial muito forte com a Praça da Alfândega, como se pode verificar nas seguintes falas dos jogadores que frequentam diariamente este espaço.

0 tempo aqui passa voando (...). Frequento estas mesas há oito anos. Este lugar é onde encontro meus companheiros de jogo. Eles estão todos os dias aqui, menos quando está chovendo. Ficamos até a noite (...) até não ver mais as pecinhas do tabuleiro".

"No dameado me dou bem. Estou aqui todos os dias. (...) Aqui somos aposentados, mas, 
tem alguns desempregados e um pessoal que trabalha por aqui perto. Todo mundo é irmão um ajuda o outro. E essa amizade se criou aqui, mesmo, nas mesas (...).

No que se refere a estes vínculos Heidrich (2001, p.77-78) afirma que:

A condição humana de estar no espaço pressupõe ter acesso a um lugar, relacionar-se, realizar a transformação e ter a consciência disto. Assim, se levarmos em consideração as mais amplas referências das integrações sociais, tais vínculos podem ser apreendidos, fundamentalmente, por meio de três expressões: apropriação, valorização e consciência.
Neste sentido, com base no mesmo autor, podese remeter que as questões da apropriação espaciais entendidas pelas territorializações conformam-se na lógica dos vínculos de afinidade, sobrevivência e/ou de experiências fazem de determinados lugares espaços da convivência social demarcada pelo sentimento de pertencimento e de identificação definidas a partir dos agrupamentos sociais, chamadas nesta pesquisa pelo conceito de agregados sociais.

Para fazer uma síntese dos dois agregados sociais analisados e para melhor elucidar a questão dos vínculos de pertencimento e laços de afetividades estabelecidos na Praça da Alfândega pode-se observar a partir do quadro explicativo organizado a seguir:

\section{0 cotidiano da Praça da Alfândega: Espaço da so- brevivência material}

Tabela 01: Agregados sociais: Vínculos Afetivos e Espaciais - Idosos e Jogadores

\begin{tabular}{|c|c|c|}
\hline \multirow{2}{*}{ Agregados Sociais } & \multicolumn{2}{|c|}{ Vínculos } \\
\cline { 2 - 3 } & Afetivos e Identitários & Espaciais \\
\hline Idosos & & \\
\hline Jogadores & Forte & Forte \\
\hline & Forte & Forte \\
\hline
\end{tabular}

Fonte: elaboração do autor

Entende-se como espaço da sobrevivência material como os espaços onde se os seres humanos utilizam na busca por um salário vital como se refere David Harvey na obra intitulada Espaços de Esperanças (2004). Ou seja, onde os indivíduos a partir de práticas sociais se apropriam de parcelas do espaço - os microterritórios - com o intuito de providenciar as condições para a sobrevivência no que se refere ao consumo de bens como alimentação e vestuário, etc.

A Praça da Alfândega conforma-se nesses espaços de sobrevivência citado, onde se nota uma infinidade de práticas de trabalho basicamente informal que visam à garantia do sustento do indivíduo. Essa realidade pode ser verificada a partir de um relato a seguir do vendedor ambulante:

Aqui é o meu 'ganha pão". "É um cafezinho aqui e ali, um doce, um 'refri' e eu vou pegando meu dinheiro, esse lugar é muito importante pra mim, aqui eu tenho, também, meus amigos e meus fregueses de sempre. cresce consideravelmente o denominado setor infor$\mathrm{mal}^{2}$ da economia que pode ser representado pelas práticas como a dos vendedores ambulantes, artesãos, profissionais do sexo, artistas de rua, etc.

Nas três fotografias a seguir podem-se perceber algumas formas de trabalho informal apresentados no cotidiano da Praça da Alfândega: um artista de rua que se estabelece de forma fixa em frente à Rua dos Andradas que pinta seus quadros com motivos da cultura gaúcha e retratos (Figura 1), um vendedor ambulante de variedades comestíveis como água, refrigerantes, doces e salgados (Figura 2) e um artista de rua que perambula pela praça usando uma fantasia de palhaço e vende por um real (ou qualquer contribuição) adereços feitos de balões (Figura 3).

Convém destacar que nas grandes metrópoles

\footnotetext{
${ }^{1}$ Referem-se a idosos os agregados que utilizam o espaço da Praça da Alfândega para práticas cotidianas vinculadas ao estar-junto, ou seja, ao convívio social interligado pelo aspecto comunicacional, geralmente estabelecido nos bancos da praça.
} 
Figura 1: Artista de rua.

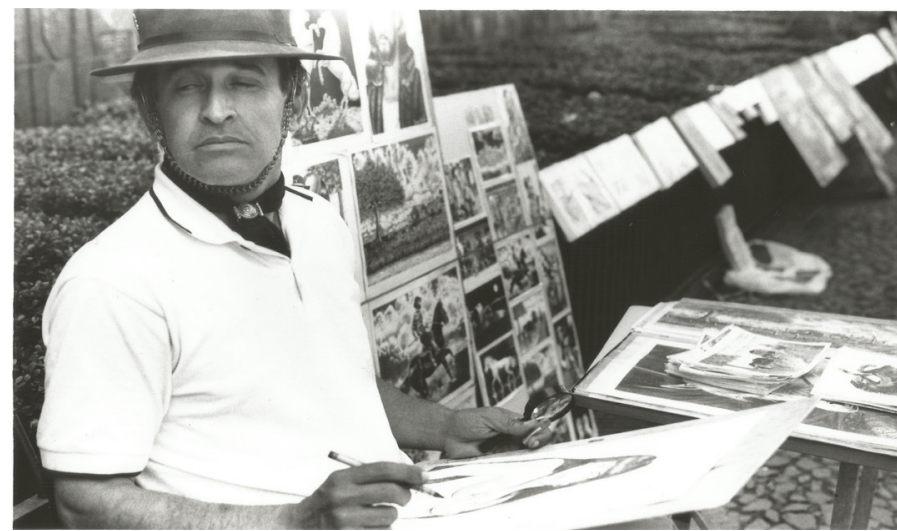

Fonte: Luciano Pedroso e Ândrio Barbosa.

Figura 2: Vendedor ambulante.

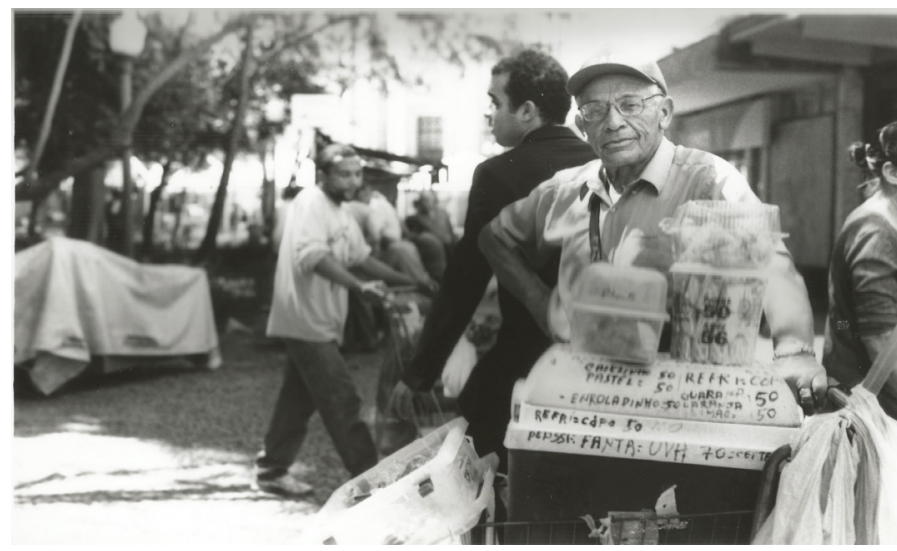

Fonte: Luciano Pedroso e Ândrio Barbosa.

Figura 3: Artista de rua.

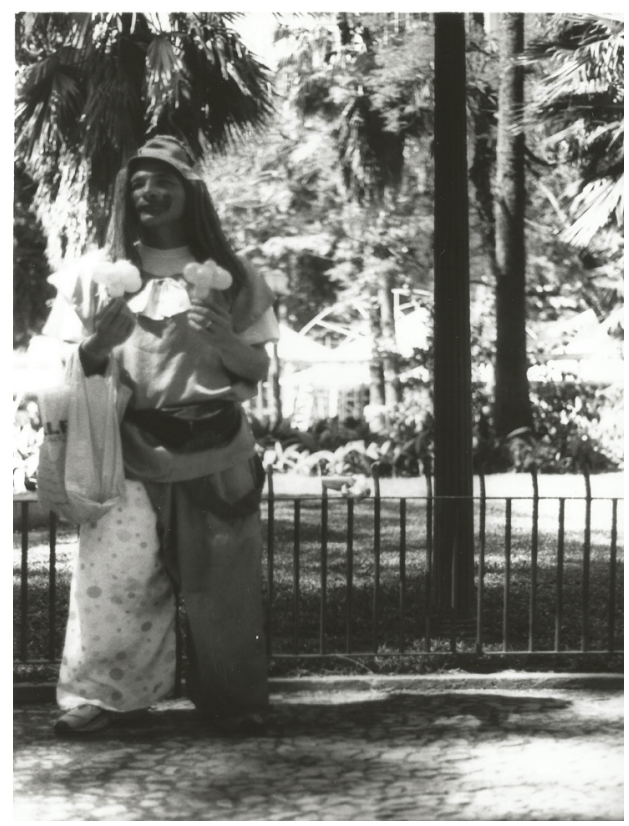

Fonte: Luciano Pedroso e Ândrio Barbosa.
Todas essas formas de trabalho convergem em práticas sociais estabelecidas nesse espaço com o intuito obter recursos financeiros para sobrevivência material. 0 que vale ressaltar que muitas dessas práticas são estabelecidas em espaços públicos, como praças, parques, ruas, calçadas, entre outros. 0 que pode estabelecer um certo conflito entre o interesse privado e o público nesses espaços comuns. Cabe ressaltar que muitas vezes o Estado não cumpre seu papel regulamentador desses espaços públicos o que promove a apropriação irregular em prol dos interesses particulares que distorcem a ideia originaria desse espaço, que seria o bem comum ou livre acesso a todos os indivíduos.

Paulo César Gomes (2002, p. 177) afirma que "o livre acesso pressupõe a não exclusividade de ninguém ou de nenhum uso diferente daqueles que são os de interesse comum", mas na realidade as grandes metrópoles brasileiras conformam-se em um processo que este autor chama de "recuo da cidadania ${ }^{3 "}$, que são percebidas no cotidiano dessas cidades que vão desde a apropriação de calçadões por camelôs, aos guardadores de carros nas ruas e até mesmo nos territórios nitidamente demarcado utilizados para a prática da criminalidade.

Neste contexto pode-se afirmar que as metrópoles modernas como Porto Alegre, conforme Haesbaert (2002, p.93) favorecem a

Grande diferenciação no tecido urbano, que cria espaços singulares, e da distribuição desigual dos equipamentos e serviços, e para além desta configuração física, há uma complexa rede de relações entre grupos que traçam laços de identidade com o espaço que ocupam, criam formas de apropriação e lutam pela ocupação e garantia de seus territórios.

A Praça da Alfândega converge nesses espaços singulares apontados por Haesbaert, no que se diz respeito às práticas sociais que ocupam e/ou utilizam este espaço visando à sobrevivência material do indivíduo. Neste contexto, pode-se registrar a atuação de vários agregados sociais como: Engraxates, vendedores ambulantes, prostitutas, artistas de rua e artesãos.

Com base nas observações e entrevistas realizadas no espaço da Praça da Alfândega com estes agregados percebeu-se grande parte dos vendedores ambulantes mantém uma certa "clientela" na praça o que de certa maneira conforma em um espaço preferencial de circulação nesse local. Esse fato não é observado, por exemplo, com os artistas de rua que variam seus espaços ao longo do dia e movimento.

\footnotetext{
${ }^{2}$ Paulo César Gomes (2002, p.177) define mercado informal como "ramo de atividade que foge do controle do Estado e, portanto de legislação vigente".

${ }^{3}$ Paulo César Gomes (2002, 174-175) define o "recuo da cidadania" como um recuo do projeto de social e espacial que conforme ele está num processo de 'encolhimento' onde a natureza da cidade muda em sua forma e sentidos, ou seja, convergem nas redefinições do projeto civilizatório.
} 
Quanto aos artesãos que se encontram na praça, mantêm, em sua maioria, seus postos de trabalho con- tinuamente na Praça da Alfândega e o redor da praça como é o caso dos artesãos que possuem estandes cre-

Tabela 02: Agregados sociais: Vínculos Afetivos e Espaciais - Artesãos, Artistas de Rua e Vendedores Ambulantes.

\begin{tabular}{|c|c|c|}
\hline \multirow{2}{*}{ Agregado Social } & \multicolumn{2}{|c|}{ Vínculos } \\
\cline { 2 - 3 } & Afetivos e Identitários & Espaciais \\
\hline Artesãos & Fraco & Forte \\
\hline Artistas de Rua & Fraco & Fraco \\
\hline Vendedores Ambulantes & Fraco & Forte \\
\hline
\end{tabular}

Fonte: elaboração do autor

denciados e autorizados pela prefeitura de Porto Alegre $^{4}$.

Na constituição desta investigação, por questões metodológicas, deu-se ênfase a alguns agregados sociais em detrimento a outros, que foram tratados separadamente nesta pesquisa, como é o caso as prostitutas e dos engraxates.

\subsection{Os engraxates da Praça da Alfândega}

"Era a Praça dos engraxates - a cadeira de braços, o chapelão de sol abrigando o freguês, a pomada embaciando o verniz do borzeguim, as escovas incansáveis fazendo chiar os calos".

\section{(Athos Damasceno)}

Os engraxates da Praça da Alfândega podem ser vistos como um dos elementos quase que obrigatório da paisagem este espaço. Encontrados nas duas extremidades da praça utilizam deste lugar para sua sobrevivência, como já foi ressaltado anteriormente, o que David Harvey (2004) denomina de "a luta por um salário vital". Esses engraxates ocupam a Praça da Alfândega há mais de cinquenta anos, sendo este lugar optado originalmente, justamente pelo aspecto da sociabilidade masculina que frequentavam os cafés do centro da cidade até meados do século passado no chamado footing da Rua da Praia que exigia dos frequentadores do centro da cidade estarem bem arrumados e seus sapatos devidamente engraxados.

Atualmente o cenário é outro, a maioria dos clientes dos engraxates são pessoas que trabalham no centro de Porto Alegre, principalmente nos escritórios e comércios do local, assim como os funcionários da
Assembleia Legislativa e do Judiciário do Estado, que para alguns entrevistados os clientes preferenciais. Localizados em sistemas fixos montados na praça cujo patrocínio dos toldos é disponibilizado pelo banco BANRISUL (Banco do Estado do Rio Grande do Sul). Os engraxates da Praça da Alfândega apropriam-se de parcelas do espaço da praça no aguardo de seus clientes, de vez em quando, abordando avidamente os transeuntes que estão com sapatos passíveis de uma graxa.

Quanto ao aspecto da sociabilidade e das práticas cotidianas que transformam este espaço percebemos variações de percepções entre os engraxates que constituem este agregado social. Dentre estas divergências de ponto de vista pode-se ser destacar como parâmetro dois relatos selecionados de dois engraxates do local.

Trabalho aqui dez anos e não tenho amizades (...). É difícil. Não gosto da cadeira e não sou dono dela. Faço meu trabalho, ganho meus trocos e só. Apenas convivo com os clientes e mais nada ${ }^{5}$." (Primeiro entrevistado)

Estou aqui já faz vinte dois anos, já vi de tudo aqui (...) a Praça da Alfândega para mim, é o meu sustento, minha alimentação, é luz, energia, é vida. Eu preciso dela e eu acho que ela precisa de mim. Aqui eu gosto de todo mundo. Me dou com todos ${ }^{6}$. (Getúlio)

Nestes relatos notam-se duas visões diferenciadas de um mesmo espaço. 0 primeiro denota-se um olhar de estranhamento do espaço e da socialidade. Nem o apego com o espaço existe. Mencionando estritamente como um espaço onde apenas ocorrem as práticas que garantem o sustento do mesmo.

Este relato remete ao conceito de topofobia

${ }^{4}$ Esses estandes credenciados participam da Feira de Artesanato da Alfândega que ocorre de segunda à sexta das 9 horas até às 18 horas e é composta por 78 expositores e fiscalizado pela SMIC (Secretaria Municipal da Produção, Indústria e Comércio).

${ }^{5} \mathrm{O}$ entrevistado não quis que o nome dele fosse mencionado na pesquisa.

${ }^{6} 0$ engraxate identificou-se como Getúlio. 
(COSTA apud RELPH, 2002, p.70-71) "desenvolvidos por Bachelard e Yi-Fu-Tuan" onde o espaço conforma-se como espaço de convivência onde se mantiveram "sensações ruins" de convívio social. Isto resulta no estabelecimento de fronteiras de convivências relacionais que marcam as territorializações. No segundo relato percebe-se uma afetividade com o espaço em questão e com a sociabilidade inerentes às práticas desenvolvidas pelo seu trabalho. A sociabilidade e a não-sociabilidade empreendidas pelos engraxates entrevistados trás à tona a ideia proposta por Maffesoli (1987, p.121-122) da chamada "socialidade eletiva" onde os indivíduos ou grupos escolhem através de "processos de atração e repulsão a forma essencial de uma sociedade". Esta realidade é verificada por intermédio de entrevistas realizadas com diversos outros engraxates o que deflagra claramente a fragmentação deste agregado onde apesar de compartilharem do espaço da Praça da Alfândega e territorializados em determinados setores da praça não estabelecem relações de afinidades entre eles e nem de pertencimento a um grupo peculiar. Muito pelo contrário nota-se um claro caráter concorrencial entre os engraxates, como se pode perceber em outro relato:

Tem um pessoal aí que rouba cliente dos outros, fazendo preço mais camarada. Aqui, meu caro, é cada um por si e Deus olha todos.

Estas constatações sobre os engraxates da Praça da Alfândega reforçam o conceito de agregado social ${ }^{7}$ proposto como elemento conceitual chave deste trabalho. A maneira como esses agregados agem em seu cotidiano remetem a ideia da "condensação instantânea" no qual menciona Maffesoli (1987, p. 107-108) onde por meio de sucessivas ambiências remetem em momentos de frágeis relações e de práticas sociais que resultam numa superficialidade da socialidade.

Esta superficialidade das relações sociais citadas por Maffesoli também é ressaltada por Bauman (2004, p.133) onde conforme este autor,

A polifonia e a diversificação cultural do ambiente urbano na era da globalização entram em cena - com a probabilidade de se intensificarem no curso do tempo - as tensões oriundas da exasperante / confusa / irritante estranheza desse cenário provavelmente continuarão a estimular impulsos segregacionistas.

Neste estudo dos engraxates da Praça da Alfândega constataram-se duas realidades distintas: a dos indivíduos que fazem do seu espaço um ambiente onde se desenvolvem práticas sociais de sobrevivência, mas com vínculos afetivos com os outros agregados e a outra perspectiva observada são as dos indivíduos que fazem desse espaço apenas como um lugar das práticas espaciais que garantem sua sobrevivência material. Esse processo do estranhamento marca profundamente o convívio desses agregados nesse espaço, visto que na maioria dos casos o outro é visto como um concorrente dos nichos de subsistência.

Esta realidade converge nesse processo de negação do sujeito enquanto participante e/ou pertencente de um grupo, assim, fortalecendo o aspecto do individualismo.

\subsection{As prostitutas da Praça da Alfândega}

"La Iglesia dice: El cuerpo es una culpa. La Ciencia dice: El cuerpo es una máquina.

Tabela 03: Agregado social: Vínculos Afetivos e Espaciais - Engraxates

\begin{tabular}{|c|c|c|}
\hline \multirow{2}{*}{ Agregados Sociais } & \multicolumn{2}{|c|}{ Vínculos } \\
\cline { 2 - 3 } & Afetivos e Identitários & Espaciais \\
\hline Engraxates & Em parte $^{8}$ & Forte \\
\hline
\end{tabular}

Fonte: elaboração do autor

La Publicidad dice: El cuerpo es un negocio. El cuerpo dice: Yo soy una fiesta". (Eduardo Galeano)

Embora a proposta da pesquisa não seja analisar a prostituição e/ ou a sexualidade no seu sentido estrito convém dizer que esse tema é muito apropriado para o estudo dos distintos padrões culturais das sociedades contemporâneas e que convergem imediatamente aos aspectos comportamentais singulares observáveis na sociedade. E, portanto servem de referências para a análise de uma série práticas sociais que resultam na

${ }^{7}$ Muito embora os engraxates da Praça da Alfândega possuam uma associação própria que cuida dos interesses destes trabalhadores. Esse fato nos remete a idéia que Morin (2003, p.169-197) propõe onde afirma que o ser humano é ao mesmo tempo egocêntrico e comunitário. Egocêntrico por conta da competição das rivalidades e diferenças e comunitário quando há interesses comuns no quadro social. Este antagonismo é chamado pelo o autor de "fitting (ajuste mútuo) e matching (rivalidade, concorrência)". 
composição de espaços como o da Praça da Alfândega.

As prostitutas da Praça da Alfândega, mais do que qualquer outro agregado social, denota uma proeminente dimensão simbólico-cultural que resultam na construção da territorialidade da prostituição neste espaço. Estas territorializações são constituídas por intermédio de uma identificação clara das mulheres que constituem este agregado específico estabelecido a partir dos seus "espaços vividos", como demonstra Félix Guattari e Rolnik (2000, p.323). Para ele,

Os seres existentes se organizam segundo territórios que os delimitam e os articulam aos outros existentes e aos fluxos cósmicos. 0 território pode ser relativo tanto a um espaço vivido, quanto a um sistema percebido no seio do qual um sujeito se sente 'em casa'. 0 território é sinônimo de apropriação, de subjetivação fechada sobre si mesma. Ele é o conjunto dos projetos e das representações nos quais vai desembocar, pragmaticamente, toda uma série de comportamentos, de investimentos, nos tempos e nos espaços sociais, culturais, estéticos, cognitivos.

No contexto da prostituição feminina em áreas públicas $^{9}$ nota-se a presença de um intenso caráter simbólico que a caracteriza, ou seja, "uma convenção tácita, não escrita, mas legível por todos os usuários através dos códigos de linguagem e do comportamento". (MAYOL, 1996, p.46). Nesse sentido no caso da Praça da Alfândega as mulheres que vivem da atividade da prostituição tem como prerrogativa básica apresentarem-se nesse espaço social no pape ${ }^{10}$ de prostituta, ou seja, essa atividade, não deve ser de caráter velado, pois as prostitutas necessitam dessa publicidade ou visibilidade, quando se refere à prostituição em locais públicos ${ }^{11}$ ou seja, elas precisam ser vistas pelos prováveis clientes.

Este fato pode ser verificado no relato de uma prostituta entrevistada:

Estamos aqui pra fazer programa não adianta a gente se esconder. Se a gente se esconde eles $^{12}$ não nos veem. E aí não vem o dinheiro para nosso sustento (...).

Questionada se havia algum preconceito quanto à prática da prostituição naquele espaço, respondeu:

Muitas pessoas olham com cara feia, trabalho há oito anos aqui, mas antes era pior. Hoje as pessoas aceitam melhor nossa profissão. Só os crentes que ainda xingam a gente. No mais nos entendemos e nos defendemos.

A outra entrevistada mencionou sobre o convívio com os outros agregados e entre elas mesmas da seguinte maneira:

Eu me dou bem com todos aqui. Os engraxates a maioria são meus amigos. Os velhinhos, alguns não gostam muito, mas outros até conversam com a gente. (...) Os jogadores vários são nossos fregueses também (...). Entre nós (as prostitutas) às vezes rolam uns atritos devido à concorrência e ao lugar que nós ocupamos. Mas geralmente a gente chega a um entendimento. Mas já vi cada briga feia".

Os limites? Tem umas meninas que têm seus pontos definidos, mas não obrigatório. E outras não. Ficam circulando e abordando alguns homens que passam. Mas têm umas que precisam ficar nos seus pontos de bataIha ${ }^{13}$, principalmente as que trabalham com gigolôs ${ }^{14}$. Assim eles (os gigolôs) podem cuidar delas.

Em relação aos conflitos de territorialidades entre os agregados sociais que frequentam espaço da Praça da Alfândega, Cláudia Fonseca ${ }^{15}$ (2005, p.261), revela que "existiam regras para manter as atividades ilícitas da praça - droga, briga roubo, e até rivalidades acirradas - dentro dos limites; senão, a prostituição não seria tão facilmente tolerada pelos integrantes das camadas médias que frequentavam o centro urbano (...)".

O espaço prostitucional da Praça da Alfândega constitui-se também em um espaço do convívio social

${ }^{8}$ Esta classificação "em parte" deve-se basicamente ao fato de que os engraxates da Praça da Alfândega apresentam um forte caráter identificatório entre eles. Muito embora, quanto aos vínculos afetivos não houve consenso neste agregado, em virtude das variadas respostas dadas durante as entrevistas realizadas.

${ }^{9}$ Modalidade de prostituição que esta pesquisa analisa. Embora se saiba que há uma intensa prática da prostituição homossexual masculina, que ocorre principalmente nos banheiros da Praça da Alfândega. Conforme Costa (2003, p.19) esta ocorre de forma oculta e em espaços pouco agradáveis devido ao "sentimento de culpa que atinge psiquicamente os homossexuais, principalmente os de classe baixa, obriga-os a segregarem-se em guetos ou territorializações pontuais, escondidas e desvinculadas de suas vidas como profissionais, filhos, amigos e, até mesmo, pais de família".

${ }^{10}$ Richard Sennett (1998, p.138-139) afirma que nas sociedades modernas os indivíduos se apresentam por meio de diversos papéis e que o torna um ator. Isso favorece a convivência e os laços sociais. "Sua identidade se baseia em fazer expressão como um trabalho de apresentação".

${ }^{11}$ Diferentemente da prostituição em domínios privados (boates, saunas, à domicílio, etc.) que usam outras formas de publicidade como por exemplos anúncios de jornais.

${ }^{12}$ Referindo-se aos clientes.

${ }^{13}$ Batalha é a designação dada para atividade da prostituição

${ }^{14} \mathrm{E}$ comum na Praça da Alfândega o próprio marido ou companheiro da prostituta assumir o papel de "gigolô" da mesma.

${ }^{15}$ Cláudia Fonseca é uma pesquisadora sobre o universo da prostituição e nesse artigo relata sua experiência em um trabalho realizado em meados da década de 1990 em Porto Alegre. 
entre as prostitutas, principalmente no que se referem à prática da prostituição estabelecida pelas profissionais do sexo idosas que fazem desse espaço um lugar da convivência entre elas. A praça torna-se um espaço de representatividade social destas mulheres. Isso é possível verificar no relato de Cláudia Fonseca (2005, p.260),

Enquanto os michês se camuflavam entre engraxates, artesãos e aposentados, virtualmente todas as mulheres ali sentadas ou paradas estavam lá para 'fazer programa' (...). A maioria das mulheres da Praça também eram mães (ou avós), mulheres vaidosas e vendedoras dos mais variados produtos. Ainda mais: nesse ambiente de sociabilidade feminina, era difícil ver chegar uma mulher cuja vida não fosse conhecida e comentada nas fofocas do grupo.
Pode-se perceber que este agregado social em sua territorialização no espaço público da Praça da Alfândega utiliza este local, sobretudo para a garantia de um salário vital que garanta sua sobrevivência material, mas também, é marcadamente verificado que a praça é um local da convivência entre elas e entre os demais agregados que compõem o cotidiano desse espaço.

Sendo assim, repercutindo significativamente nas práticas sociais (vínculos identitários e afetivos) e espaciais (vínculo com o lugar vivido) estabelecidas na Praça da Alfândega. Como pode ser notado no seguinte quadro explicativo:

$\mathrm{Na}$ investigação do cotidiano desse agregado social que se estabelece neste complexo espaço no centro de uma grande metrópole, deparou-se, inevitavelmente, com a realidade vivenciada pelas profissionais do sexo na Praça da Alfândega. E para compreender esta realidade torna-se imprescindível mencionar que o universo da prostituição na Praça da Alfândega é mar-

Tabela 04: Agregados sociais: Vínculos Afetivos e Espaciais - Prostitutas

\begin{tabular}{|c|c|c|}
\hline \multirow{2}{*}{ Agregados Sociais } & \multicolumn{2}{|c|}{ Vínculos } \\
\cline { 2 - 3 } & Afetivos e Identitários & Espaciais \\
\hline Prostitutas & Forte & Forte \\
\hline
\end{tabular}

Fonte: elaboração do autor

cado, também, por um forte caráter simbólico inerente a prática desta atividade.

Este caráter simbólico, que converge consequentemente ao aspecto da identidade social ${ }^{16}$, emerge principalmente na expressão estética (roupas e maquiagens) e vocabulário próprio utilizado principalmente entre elas. A identidade social está pautada justamente, pela necessidade da publicidade, ou seja, da exposição da prática da prostituição ao meio social (neste caso a Praça da Alfândega) que ela se encontra inserida.

\section{Considerações Finais}

0 estudo do cotidiano em uma praça na grande cidade nos remete a uma investigação da multiplicidade de fenômenos sociais que se estabelecem por uma rede de socialidade em territorialidades descontínuas. Por isso a escolha da metodologia apropriada foi de extrema relevância. Onde a fotografia e a entrevista social tiveram um papel significante no desvendamento das práticas sociais dos agregados neste espaço público.

Com relação aos agregados cabe reafirmar que os mesmo retratam uma condição contemporânea presente nos grandes centros urbanos onde os processos sociais na maio- ria das vezes são estabelecidos de formas superficiais empreendidas por meio de uma rede de conexões, cuja duração é definida pela efemeridade.

A partir das constatações verificadas com este estudo percebe-se que a Praça da Alfândega se apresenta como um mosaico de inúmeras representações sociais de variados e diferenciados códigos que marcam esse espaço público, como um espaço onde convergem interesses divergentes entre os agregados sociais analisados.

Onde o espaço como a necessidade da convivência (socialidade e afetividade) e o espaço como necessário à sobrevivência (subsistência material). E a partir disso, não apenas se trouxe à tona aspectos sobre a convivência e a identificação das pessoas nesta praça, mas também, a maneira com que muitos lutam para sobreviver e garantir seu salário vital no contexto das sociedades urbanas contemporâneas.

A cidade é um local privilegiado para o estudo do cotidiano em virtude da variada gama de modos de vida e representações simbólicas que se percebem nos espaços urbanos. O espaço vivido urbano é repleto de significados, histórias, imagens, etc. Onde, toda essa polissemia presente no cotidiano metropolitano torna-se passível a analise de uma série de fenômenos verificados nesse espaço.

Sendo assim, o estudo do cotidiano dos agregados sociais são também, as análises dos projetos de vida empre-

\footnotetext{
${ }^{16}$ A identidade social de acordo com João de Pina Cabral (2003, p.3-4) e aquela assumida pelo indivíduo e que remete à prática social podendo ela ser oposta à identidade individual. Esta identidade social é construída a partir da memória interligada pelo o aspecto da "diferenciação/identidade".
} 
endidos no tempo-espaço deste espaço público, expressos pelas capacidades transformadoras e criadoras que os agregados sociais possuem e que visam basicamente sua sobrevivência material e afetiva. Este convívio é assinalado por uma série de aspectos que se remetem às questões da indiferença e da rejeição produzida ou como se refere De Certeau (1994) na "invenção do cotidiano" dos indivíduos que ambientam este espaço social metropolitano, chamado de Praça da Alfândega.

\section{Referências}

BAUMAN, Zygmunt. Amor líquido: sobre a fragilidade dos laços humanos. Rio de Janeiro: Jorge Zahar Ed. 2004.

BOURDIEU, Pierre. 0 poder simbólico. 4. ed. Rio de Janeiro: Bertrand Brasil, 2001.

CABRAL, João de Pina. Identidades inseridas: algumas divagações sobre identidade, emoção e moralidade. Instituto de Ciências Sociais da Universidade de Lisboa, Lisboa, junho de 2003. Acesso em <www.ics.ul.pt/publicacoes/workingpapers/ wp2003/WP2-2014. pdf> Acesso em $12 / 08 / 14$

CAMPOS, Heleniza Ávila. Refletindo sobre o papel das representações nas territorialidades urbanas: o exemplo da área central do Recife. GEOUSP - Espaço e Tempo, São Paulo, n. 11, p.35-50, 2002.

CANEVACCI, M. Massimo. A cidade polifônica. São Paulo: Studio Nobel, 1993.

CERTEAU, Michel de. A invenção do cotidiano: artes de fazer. Rio de janeiro: Vozes, 1994.

COSTA, Benhur Pinós da. Territorializações: ações de agregados sociais. Caesura, Canoas, n. 21, p.67-71, jul/ dez, 2002

COSTA, Benhur Pinós da. A condição homossexual e a emergência de territorializações. In: Dimensões históricas da relação entre espaço e cultura - Reunião Internacional da Comissão de Geografia Cultura. Anais em CD-ROM, Rio de janeiro, 2003.

ESTEVES, João Pissara. Espaço público e democracia: comunicação, processo de sentido e identidade social. São Leopoldo: Unisinos, 2003.

FONSECA, Cláudia. A morte de um gigolô: fronteiras da transgressão e sexualidade nos dias atuais. In: PISCITELLI, Adriana; GREGORI, Maria Filomena; CARRARA, Sérgio (orgs). Sexualidade e saberes: convenções e fronteiras. Rio de Janeiro: Garamond, 2005.

FOUCAULT, Michel. Microfísica do poder. 10. ed. Rio de Janeiro: Graal, 1992.

FREUD, Sigmund. 0 futuro de uma ilusão: o mal-estar na civilização. v. 21. Rio de Janeiro: Imago, 1974.

GOMES, Paulo César da Costa. A condição urbana: ensaios de geopolítica da cidade. Rio de janeiro: Bertrand Brasil, 2002.
GUATTARI, Félix, ROLNIK, Suely. Micropolítica: Cartografias do desejo. 6. ed. Petrópolis: Vozes, 2000.

HAESBAERT, Rogério. Des-territorialização e identificação: a rede gaúcha no nordeste. Niterói: EDUF, 1997.

HAESBAERT, Rogério. Territórios alternativos. São Paulo: Contexto, 2002.

HALL, Stuart. A identidade cultural na pós-modernidade. 2. ed. Rio de Janeiro: DP\&A, 1998.

HARVEY, David. Espaços de esperança. São Paulo: Loyola, 2004.

HARVEY, David. Condição pós-moderna. 12. ed. São Paulo: Loyola, 2003.

HEIDRICH, A. L.; CARVALHO, Orlando Albani de. Territorialidades de exclusão e inclusão social: relações da sociedade com o espaço em situações de pobreza e de construção de vida econômica e de consciência. In: VIII Encuentro de Geógrafos de América Latina, 2001, Santiago: Universidad de Chile, 2001. v. 1. p. 74-80.

LAITANO, Gisele Santos. Os Territórios, os Lugares e a Subjetividade: construindo a geograficidade pela escrita no movimento hip hop, no bairro Restinga, em Porto Alegre/RS. Porto Alegre, 1991. Dissertação (Mestrado em Geografia). UFRGS.

MAFFESOLI, Michel. 0 tempo das tribos; o declínio do individualismo nas sociedades de massa. Rio de Janeiro: Forense- Universitária 1987.

MAFFESOLI, Michel. o conhecimento comum: compêndio de sociologia compreensiva. São Paulo: Editora Brasiliense, 1988.

MAFFESOLI, Michel. A parte do diabo: resumo da subversão pós-moderna. São Paulo: Record, 2004.

MAFFESOLI, Michel. 0 mistério da conjunção: ensaios sobre comunicação, corpo e socialidade. Porto Alegre: Sulina, 2005.

MAYOL, Pierre. Morar. In: CERTEAU, Michel; GIARD, Luce; MAYOL, Pierre (orgs.). A invenção do cotidiano 2: morar, cozinhar. Petrópolis: Vozes, 1996.

MESQUITA, Zilá. Cotidiano ou quotidiano? In: MESQUITA, Zilá; BRANDÃO, Carlos Rodrigues (orgs). Territórios do cotidiano. Porto Alegre/ Santa Cruz do Sul: Ed. Da Universidade/ Edunisc,1995.

MORIN, Edgar. 0 método 4: as idéias.3. ed. Porto Alegre: Sulina, 2002.

OLIVEIRA, Pérsio Santos de. Introdução à sociologia. São Paulo: Ática, 2005.

PEDROSO, Luciano Fernandes. 0 estudo dos espaços públicos metropolitanos: a praça da alfândega em Porto Alegre o cotidiano dos agregados sociais. 2007. 137f. Dissertação (Mestrado em Geografia) - Instituto de Geociências. Programa de Pós-graduação em Geografia. Universidade Federal do Rio Grande do Sul, Porto Alegre.

PICCINI, Mabel. Sobre a comunicação nas grandes ci- 
dades. OPINIÃO PÚBLICA, Campinas, Vol IX, no 2, Outubro, 2003, pp. 01- 19.

SACK, Robert. The human territoriality: its theory and history. Cambridge: Cambridge University Press, 1986.
SANTOS, Milton. A natureza do espaço: técnica e tempo, razão e emoção. São Paulo: Hucitec, 1997.

SENNETT, Richard. 0 declínio do homem público: as tiranias da intimidade. São Paulo: Companhia da Letras, 1998.

\title{
THE STUDY OF TH PUBLIC AND METROPOLITAN SPACES: PRAÇA DA ALFÂNDEGA IN PORTO ALEGRE AND THE EVERYDAY LIFE OF SOCIAL AGGREGATES
}

\begin{abstract}
Resumo: This paper analyzes the everyday life of social aggregates found in Praça da Alfândega (Alfândega Square), located in the downtown area of Porto Alegre, state of Rio Grande Sul. The aspects of relationship and identity, the subjective and aesthetic expressions, the social borders as well as the territorializations engaged in by individuals who compose these social aggregates are investigated. In addition, relevant issues concerning the function of public space, citizenship and aspects of the forms of sociability and unsociability in modern metropoles are discussed as well. The Praça da Alfândega, as a mosaic of social representations, juxtaposed territories and signs, constitutes an important locus of analysis of urban space, presenting itself as a dichotomic space both of material survival and of social living for the forms called social aggregates. For this reason, the study of everyday life in social aggregates found in Praça da Alfândega is also an investigation of recent urban phenomena and their several and emergent social practices according to ways of life, symbolical forms, and the use of spaces in metropoles.
\end{abstract}

Key words: Every day life - Social aggregate - Urban space - Identity 